\title{
Speech Community and SLA
}

\author{
Changjuan Zhan \\ School of Foreign Languages, Qingdao University of Science and Technology, Qingdao, Shandong, China
}

\begin{abstract}
The notion of the speech community is one of the foci and the main issue of analysis in the ethnography of communication and one of the important concepts in sociolinguistics. In the theory and method of sociolinguistics, it is one of the major problems concerned. Second language acquisition (SLA) is a sub-discipline of applied linguistics and is defined as the learning and adopting of a language that is not your native language as well as the process by which people learn it. SLA is influenced by many factors in a speech community. This paper presents a detailed analysis of speech community; discusses different theories concerning SLA; summarizes the various factors in a speech community which function to influence SLA; and tries to point out the significance of the study and the problems existing in it.
\end{abstract}

Index Terms — speech community, second language acquisition, definition, influence, sociolinguistic

\section{INTRODUCTION}

In most sociolinguistic and anthropological-linguistic research, the speech community has always been the focus. It is one of the main problems and the major objective of study in the ethnography of communication, in addition, it is also one of the important issues in sociolinguistics. In the theory and method of sociolinguistics, it is one of the major problems concerned. Second language acquisition (SLA) is a sub-discipline of applied linguistics and is defined as the learning and adopting of a language that is not your native language as well as the process by which people learn it. SLA is influenced by many factors in a speech community. This paper discusses the various definitions of the speech community proposed by different linguists; tries to present a detailed analysis of this notion; discusses different theories concerning SLA; summarizes the various factors in a speech community which function to influence SLA; and tries to point out the significance of the study and the problems existing in it.

\section{AN ANALYSIS OF SPEECH COMMUNITY}

\section{A. Definitions of Speech Community from Different Linguists}

For general linguistics, a speech community is all the people who speak a single language and so share notions of what is same or different in phonology or grammar. This would include any group of people, wherever they might be, and however remote might be the possibility of their ever wanting or being able to communicate with each other, all using the same language. Sociolinguists, however, focus on the language practices of a group of people who do in fact have the opportunity to interact and who, share not just a single language but a repertoire of languages or varieties. Different linguists defined it differently:

Lyons (1970) defined it as "All people who use a given language or dialect" This definition was rather simple and general with the focus on a given language or dialect.

For Fishman (1971), a Speech community is a subtype of community "all of whose members share at least a single speech variety and the norms for its appropriate use". In this definition, he put forward the concept of speech variety and norms of usage which was a great step forward.

Labov (1972) defined it as: "Participation in a set of shared norms; these norms may be observed in overt types of evaluative behavior, and by the uniformity of abstract patterns of variation which are invariant in respect to particular levels of usage" He proposed the first definition of speech community and his perspective was most influential in that it emphasized on linguistic production, social perception and evaluation. It gave an insight to the essence of this term and has been followed by all the subsequent scholars.

Gumperz (1968) held that it was: "any human aggregate characterized by regular and frequent interaction by means of a shared body of verbal signs and set off from similar aggregates by significant differences in language usage". Later he revised it as "A social group which may be either monolingual or multilingual, held together by frequency of social interaction and set off from the surrounding areas by weaknesses in the lines of communication"(1971) He focused on the aspect of interaction and multilingual which is very important feature of the speech community.

For Hymes (1974), however, the Speech community is "not a naive attempt to use language to compass a social unit", but rather "an object defined for purposes of linguistic inquiry", not to be confused with "attributes of the counterpart of that object in social life... It postulates the unit of description as a social, rather than linguistic, entity" Then, Hymes (1986) proposes to divide the speech community into individual communities and groups, which is considered a descriptive theory including two aspects: a community that shares "rules for the conduct and interpretation of speech, 
and rules for the interpretation of at least one linguistic variety". Thus, he was concerned with approaches of speaking and communicative competence.

Kerswill (1994) believed it referred to "linguistic similarities among the various codes in use", and to "agreement on the social meaning of various linguistic parameters", including sociolinguistic variables, codeswitching, and contextualization cues; such parameters can only be fully understood by members of the same speech community (liu Mingzheng, 2012). He took the perception and motivation of the individual speaker as primary.

These definitions reflect different concerns of each researcher, but it turns out that most linguists emphasized the shared rules of language use and the common communication among the members in a speech community. And it's also the basic concept in the study of the speech community.

\section{B. My Interpretation of the Speech Community}

After studying all this, I find it is difficult to give the speech community an exact definition. But this study helps me a lot in having a deeper and better understanding of this notion. In the ethnography of communication and in sociolinguistics, speech community is related more strictly to social interactional conditions. And the members in a speech community must have shared language use, shared norms of speech performance, shared value and interpretation of language, and shared sociocultural knowledge. I tried to summarize my understanding of the speech community as follows:

1. The Speech community is the principal unit of analysis in the ethnography of communication and sociolinguistics. It is an abstract "space" studied in sociolinguistics, where a complex interlocking social network of communication takes place, and through frequent, rule-governed interaction and the use of shared speech norms and a common linguistic repertoire of signs, the members in it constitute a group which is distinguished from others by significant differences in language use. So there is a linguistic component and a social component in this concept.

2. In this interpretation of the speech community, speech norms are the unstated rules for use of a language that are shared by members of a speech community. We assume that all the members in a speech community have only one series of norms in language use when speaking. Some of these norms embrace common rules for assessing such as making judgments, understanding problems and explaining language use, which helps people in one speech community to recognize members form other speech communities. For example, we often feel that someone "sounds funny" or "has an accent" or "isn't from around here", that's due to the fact that they don't share the speech norms with us. Linguistic repertoire refers to the linguistic resources of a person or a community.

The idea of the sharing norms and repertoire or varieties is important. Though the members in a speech community might not all know and use each of the varieties, they recognize the conditions under which other members of the community believe that it is appropriate to use each of them. For example, Londoners recognize Cockney and Mayfair varieties of English though they may themselves use neither. Another example is in some small Israeli Palestinian villages, there are commonly four significant varieties making up the linguistic repertoire: the village vernacular, a dialectal variant of Palestinian Arabic, which is considered appropriate for most daily activities; Classical or Modern Standard Arabic, which is used only in educational or religious or formal public functions; Modern Israeli Hebrew, kept for use outside the village; and some school-learned English, for educational use.

3. In addition, there is no theoretical limitation on the location and size of a speech community. The members in a speech community may be far away from each other, for example, there are a variety of dialects. If speaks can understand each other's dialects well, they just consider that they belong to the same speech community despite the fact that their homes may be far away from each other. A small social network (such as regular patrons of a football team) forms a speech community, and so does a large metropolis or a country, a region, or a communication network, like the internet.

4. What is also worth noticing in this notion is that the members of a speech community only share some experiences such as knowledge about and attitude towards a set of language varieties, but not necessarily the same language. For instance, Spanish speakers in some states of America and in some countries of south America all speak one language, but they are members of different speech communities. Whereas in some speech communities in South Pacific, the couples in one family may speak different languages but they belong to one same speech community.

\section{SeCOND LANGUAge ACQUisition}

\section{A. Definition of SLA}

Second language acquisition (SLA) is the process by which people learn a second language. It also refers to the scientific discipline devoted to studying that process. Second language refers to any language learned in addition to a person's first language; although the concept is named second-language acquisition, it can also incorporate the learning of third, fourth, or subsequent languages (http://en.wikipedia.org, Mar, 2013). So according to the above analysis of speech community, there may be a variety of different language in one speech community, which makes SLA research more difficult.

Second-language acquisition is a sub-discipline of applied linguistics. It is a comparatively new research field and is based on many other subjects. As well as the various branches of linguistics, second-language acquisition is also closely related to psychology, cognitive psychology, and education. SLA research began as an interdisciplinary field, and 
because of this it is difficult to identify a precise starting date. However, it does appear to have developed a great deal since the mid-1960s. The term acquisition was originally used to emphasize the subconscious nature of the learning process, but in recent years learning and acquisition have become largely synonymous (http://en.wikipedia.org, Mar, 2013).

Generally speaking, Second-language acquisition does not include bilingualism. Most linguists hold that bilingualism is the final result, but not the process of learning a language. And they consider this term as something like the fluency in their native language. However, researcher in many other fields like education and psychology, often use the term roughly to refer to all forms of multilingualism. There also exist difference between Second-language acquisition and the acquisition of a foreign language. Of course, second language acquisition and learning foreign languages share the same basic procedure in different settings.

Researchers have all along been debating as to how on earth is language learned, but a lot of problems haven't been resolved yet. As for second-language acquisition, there are many different theories but so far there is no consensus concerning the final and perfect and absolute definition and explanation of this term. Owing to the fact that the study of second language acquisition is a multi-field task, Due to the interdisciplinary nature of the field of second-language acquisition, there will be a long way to go before we fulfill the final satisfactory definition and explanation of this term.

\section{B. Theories of SLA}

S. Krashen developed the monitor theory over a number of years since 1975. It was first designed not as a second language acquisition theory but as a model of second language performance of second language learners. Krashen (1982a) formalized this theory in five hypotheses, dealing with the laws governing L2 acquisition. The five hypotheses are as follows:

1. The acquisition-learning hypothesis. Krashen claims that adults have two ways of getting to master a second language, whose process is distinctive and independent. One way is language acquisition. It is a process unconscious to the acquirers and is much the same as the way children acquire their first language. The acquirers of the second language are usually unaware that they are acquiring a language, instead, they are only aware that they are making use of the language to exchange with others. They are also unconscious that they have acquired the language as well as the competence in using the language. The other way to have a good command of a second language is by language learning. This is a conscious process. The learners are conscious that they are learning a second language, knowing the rules and being able to talk about them. The acquisition-learning hypothesis claims that acquisition is a very powerful process in the adult, that the capability to "pick up" languages does not disappear in childhood, and that correcting mistakes have very little or even no impact on the subconscious acquisition, although researchers consider it helpful for the conscious learning process.

2. The monitor hypothesis. This hypothesis holds that acquisition and learning are used in very specific ways. Usually acquisition makes a person speak in the second language is the key factor for his/her fluency, whereas there is only one function of learning, that is , to edit or monitor the language in use. Learning only has the function of changing the forms of our spoken words after they are uttered by the acquired language. This hypothesis implies that conscious learning of formal rules only has a minor function in mastering the second language. Many people are against this theory.

3. The natural order hypothesis. This hypothesis claims that in acquiring a second language, usually the acquisition of the structure in grammar has its feature of being a foreseeable and natural order, no matter how different the acquirers' ages and language backgrounds are. The implication is that the sequencing of grammar is neither desirable nor necessary when our goal is language acquisition. But when our goal is conscious learning, sequencing is necessary and unavoidable.

4. The input hypothesis. It claims that we acquire by understanding language that contains structure a bit beyond our current level of competence (i.e. " $i+1$ "). This is done with the help of context or extra-linguistic information. When communication is successful, and when the input in understood and there is enough of it, " $i+1$ " will be provided automatically. Hence production ability emerges. It cannot be taught directly. According to Krashen, the input hypothesis predicts that the classroom may be an excellent place for second language acquisition because within an hour in the classroom, we can provide comprehensible input of a whole day outside. (Meiyun Yue, 1999).

5. The affective filter hypothesis. This hypothesis captures the relationship between affective variables such as anxiety, motivation and self-confidence and the process of second language acquisition by positing that acquirers vary with respect to the strength or level of their affective filters. It claims that the influence of affect is "outside" the language acquisition itself. It implies that our pedagogical goals should not only include supplying comprehensible input but also creating a situation that encourages a low filter (Meiyun, Yue, 1999).

Krashen summarizes his second language acquisition theory as follows: Acquisition is of more significance than learning; two conditions are necessary for acquiring a second language---comprehensible input containing structures a bit beyond the acquirer's current level; and a low or weak affective filter to allow the input "in". Krashen concludes that comprehensible input and the strength of the filter are the true causes of second language acquisition. (Meiyun, Yue, 1999). 
As is motioned above, the Speech community is the principal unit of analysis in the ethnography of communication and sociolinguistics. And in fact, it may refer to any research in linguistics that is involved in people's natural speech and all the recorded data. It is at the intersection for which the researchers try to analyze and describe and explain. And it is inescapable in studying language variation and change both geographically and socially, ways of speaking, and patterns of choice among elements in a linguistic repertoire. It is thus a main objective of description and theorizing in our study. According to the above summary and analysis, the research of SLA has many different sociolinguistic approaches. All these approaches have one thing in common, that is, they don't consider language as a purely psychological phenomenon; on the contrary, the social context in which language is learned is viewed by most sociolinguistic researchers as vital for an appropriate comprehension of the acquisition process.

Rod Ellis identifies three types of social structure which can affect the acquisition of second languages: socialinguistic setting, specific social factors, and situational factors. Socialinguistic setting refers to the role of the second language in society, such as whether it is spoken by a majority or a minority of the population, whether its use is widespread or restricted to a few functional roles, or whether the society is predominantly bilingual or monolingual. Ellis also includes the distinction of whether the second language is learned in a natural or an educational setting. Specific social factors that can affect second-language acquisition include age, gender, social class, and ethnic identity, with ethnic identity being the one that has received most research attention. Situational factors are those which vary between each social interaction. For example, a learner may use more polite language when talking to someone of higher social status, but more informal language when talking with friends (http://en.wikipedia.org, Mar, 2013).

Speech community and SLA both emphasize shared community membership and linguistic interaction. Combing Krashen's input and affective filter hypothesis with Rod Ellis's three types of social structure which can affect SLA, this paper summarizes the factors in a speech community which influence SLA as follows:

\section{A. Community Attitudes.}

Community attitudes toward the language being learned can have a profound impact on SLA. The process of second language acquisition is stressful and the positive or negative attitude from the surrounding society in a speech community can be impactful. As is stated in Krashen's affective filter Hypothesis, acquirers vary with respect to strength or level of their affective filters such as anxiety, motivation and self-confidence. Consequently, the more positive the community attitude is, the more effective will the second language be acquired. In general, positive attitudes toward second language, its speaker and its cultre can enhance learning, which can in turn be influenced by this success; negative attitudes can impede learning. According to Schumann's acculturation model, Learners' rate of development and ultimate level of language achievement is a function of the "social distance" and the "psychological distance" between learners and the second-language community. Social factors in a speech community are most important, but the degree to which learners are comfortable with learning the second language also plays a role.

\section{B. Social Context in a Speech Community}

Many languages are now wildly used as international languages. In every social interaction, they act as the means of communication between speakers of different countries in different social context such as doing business, conducting scientific study or having a daily small talk. To achieve better second language acquisition, the learners should involve themselves in various resources of the language. The Input Hypothesis states that human acquire language in only one way-by understanding messages or by receiving "comprehensible" input". Language differ from one domain form another, for example, the language of physics is not the same as the language in politics. To acquirers of a second language, the most important thing is to understand and fact and persevere in learning it. The potential learning outcomes are associated with different social context.

\section{Specific Social Factors in a Speech Community}

A variety of specific social factors in a speech community can affect second language acquisition such as age, gender, social class, and ethnic identity. Besides, the role of the second language in the speech community, such as whether it is spoken by a majority or a minority of the population, whether its use is widespread or restricted to a few functional roles, or whether the society is predominantly bilingual or monolingual all play a vital part in SLA. Take gender as an example. It is commonly believed that females are better at second language acquisition than males. Women are more sensitive to the language forms such as pronunciation, expression, oral language, etc. and are more willing to employ them in their speech. In this way they may be more likely to avoid making use of any interlingua forms which are different from the targeted language forms. However, when it comes to comprehension, grammar, analysis, the differences between females and males are not so clear. So it is commonly believed that gender difference exerts some influence on second language acquisition. Another case in point is ethnic identity. Most socio-psychological research has shown that language and ethnic identity are related to each other. In a speech community, one group of people will choose the language fits for their ethnic identity. Within the social psychology of identity, two components are involved: personal identity and social identity. A person's native dialect or language shapes his personal identity, whereas the environment in his speech community, his educational process in the speech community develop his social identity.

\section{SignificANCE AND PROBlems}


The speech community has always been the focus in most sociolinguistic and anthropological-linguistic research. It is one of the main problems and the major objective of study in the ethnography of communication, in addition, it is also one of the important issues in sociolinguistics. It is involved with all linguistic research that is concerning the naturally-occurring speech or recorded data. It represents the social boundaries within which analysts locate and seek to describe and account for. And it is inescapable in studying language variation and change both geographically and socially, ways of speaking, and patterns of choice among elements in a linguistic repertoire. SLA is a subdiscipline of applied linguistics and is defined as the learning and adopting of a language that is not your native language as well as the process by which people learn it. SLA is influenced by many factors in a speech community. Thus the study of speech community is equally important as other basic notions such as "language", "dialect" or "grammar" as a primary object of description and theorizing in our study of its influence on SLA. And the study will be of great significance to second language teaching as well.

Yet there still exist some problems concerning this issue. First of all, there is remarkably little agreement or theoretical discussion of the concept in sociolinguistics, though it is much defined. Then, the survey of its application seems hard to be exhaustive. Next, in order to have a scientific and detailed study of the shared language varieties, we must examine speech in natural settings, not artificial ones. But how do we get at this kind of speech? As we know the "Observer's paradox": the speech we most want to observe is unobserved speech, we have to come up with techniques for overcoming this. Besides, the principal concepts of speech community have received reactions and modifications of two broad types: variations on a theme, intended to refine (usually broaden) a speech community model; and general rejection of their applicability, on various grounds. Which one should be followed? Finally, the speech community should not be taken for a unit of social analysis; and we ought not to assume speech community exist as predefined entities waiting to be researched, or identify them with folk notions, but see them as objects constituted anew by the researcher's gaze and the questions we ask. So, we still have a long way to go to get a better job done in studying the notion of the speech community and its influence on SLA.

\section{REFERENCES}

[1] Fishman, J.A. (1971). Sociolinguistics. Newbury House.

[2] Gumperz, John. (1968). The speech community. International encyclopaedia of the social sciences: 381-6. Macmillan.

[3] Gumperz, John. 1(971). Language in social groups. Stanford: Stanford University Press.

[4] Kerswill, P. (1994). Dialects converging: Rural speech in urban Norway. Oxford: Oxford University Press.

[5] Lyons, J. (Ed.). (1970). New directions in linguistics. London: Penguin.

[6] Labov, W. (1972). Sociolinguistic patterns. Philadelphia: University of Pennsylvania Press.

[7] Meiyun Yue. (1999). Applied Linguistics. Nanjing Normal University Press.

[8] Muriel Saville-Troike. (2008). The Ethnography of Community. USA: Blackwell Publishing.

[9] http://en.wikipedia.org, Mar, 2013.

Changjuan Zhan was born in Longkou, China in 1963. She received her Bachelor's degree of English Education in Shandong Normal University in 1985.

She is currently an associate professor in the college of foreign languages, Qingdao University of Science and Technology, Qingdao, China. Her research interests include applied linguistics and English language teaching. 